\title{
Surgical Methods of Zygomaticomaxillary Complex Fracture
}

So Young Ji, Seung Soo Kim, Moo Hyun Kim, Wan Suk Yang

Department of Plastic and Reconstructive Surgery, Dong Kang General Hospital, Ulsan, Korea
No potential conflict of interest relevant to this article was reported.
Background: Zygoma is a major buttress of the midfacial skeleton, which is frequently injured because of its prominent location. Zygoma fractures are classified according to Knight and North based on the direction of anatomic displacement and the pattern created by the fracture. In zygomaticomaxillary complex (ZMC) fracture many incisions (lateral eyebrow, lateral upper blepharoplasty, transconjunctival, subciliary, subtarsal, intraoral, direct percutaneous approach) are useful. We reviewed various approaches for the treatment of ZMC fractures and discussed about incisions and fixation methods.

Methods: A retrospective review was conducted of patients with ZMC fracture at a single institution from January 2005 to December 2014. Patients with single zygomatic arch fracture were excluded.

Results: The identified 694 patients who were admitted for zygomatic fractures from which 192 patients with simple arch fractures were excluded. The remaining 502 patients consisted of 439 males and 63 females, and total 532 zygomatic bone was operated. Orbital fracture was the most common associated fracture. According to the Knight and North classification the most frequent fracture was Group IV. Most fractures were fixated at two points $(73 \%)$.

Conclusion: We reviewed our cases over 10 years according to fracture type and fixation methods. In conclusion, minimal incision, familiar approach and fixation methods of the surgeon are recommended.

Keywords: Zygomatic fractures / Maxillary fractures / Maxillofacial injuries

\section{INTRODUCTION}

The zygomaticomaxillary complex (ZMC) is a major buttress of the midfacial skeleton. The ZMC is important to structural, functional, and aesthetic appearances of the facial skeleton. A ZMC fracture is also known as a tripod, tetrapod, or quadripod fracture, trimalar fracture or malar fracture [1,2]. Management of $\mathrm{ZMC}$ fractures is a frequent challenge in plastic surgery. The surgical approach is devised based on the findings from the physical examination and imaging studies. Adequate exposure and mobilization of the fracture fragments are critical for ensuring appropriate anatomical reduction. In this article, we reviewed various reduction methods and instruments and discussed fracture types and reduction methods. We also reviewed one point fixation of various areas, various two point fixation methods, and a three point fixation method in the literature. We then reviewed our cases over 10 years according to fracture type and fixation methods.
Correspondence: Wan Suk Yang

Department of Plastic and Reconstructive Surgery, Dong Kang General Hospital, 239

Taehwa-ro, Jung-gu, Ulsan 44455, Korea

E-mail: artps@naver.com

Received September 2, 2016 / Revised December 15, 2016 / Accepted December 15, 2016

\section{METHODS}




\section{Study patients}

A retrospective review was conducted of patients with $\mathrm{ZMC}$ fracture at a single institution from January 2005 to December 2014. Patients with single zygomatic arch fracture were excluded. The fracture type was classified according to the Knight and North classification [3] based on computed tomography (CT) images obtained before surgery.

\section{Surgical method}

Under general anesthesia and surgical preparation, the fracture sites were approached via subcilliary and lateral eyebrow incision. A superior gingivobuccal approach was used for unstable fractures when necessary. According to the fracture pattern, various reduction methods were performed. In group III (unrotated body fracture with displacement), a Langenbeck elevator was used for reduction through a lateral eyebrow approach. The Langenbeck elevator was placed under the zygomatic body and the posteriorly displaced body segment was pushed to anterior using a lever fulcrum made with kelly wrapped by gauze. In group IV (medially rotated body fracture), if the method of group III is not properly applicable, the plate was screwed to the lateral fracture segment of the inferior orbital line and the small bone hook was pulled laterally. Then the reduction can be performed properly (Figs. 1,2). In group V (laterally rotated body fracture), the plate was screwed to the lateral fracture segment of the inferior orbital rim and pulled medially (Figs. 3, 4). In group VI (complex comminuted injury), avoiding excessive periosteum exposure, the plate was fixed after reducing the horizontal and vertical main buttress, and small bone fragments were placed to bone defects below the periosteum [2].

After reduction is performed, plates should be placed on the lateral orbital rim and inferior orbital rim. If fixation of the plate in the lateral orbital rim and inferior orbital rim is not stable enough, one more plate should be placed on the zygomaticomaxillary buttress via gingivobuccal incision. After the operation, we checked X-ray (water's view, zygomatic arch view) or CT, and evaluated the X-ray again after one month.

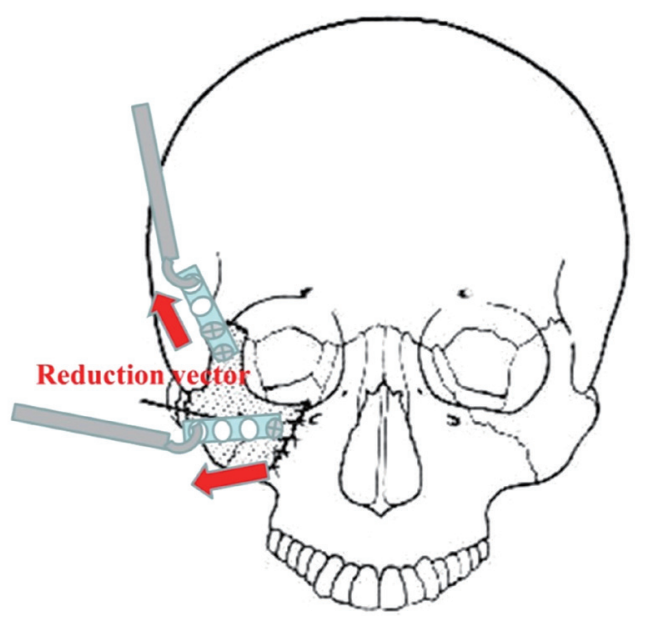

Fig. 1. Reduction with plate and screw. A $1.5 \mathrm{~mm}$ plate with a $4.0 \mathrm{~mm}$ screw fixed on the lateral fracture segment of the inferior orbital rim, and the fracture is reduced by pulling the plate anterior-laterally with a small bone hook. After the reduction screw is fixed on the medial segment of the inferior orbital rim.
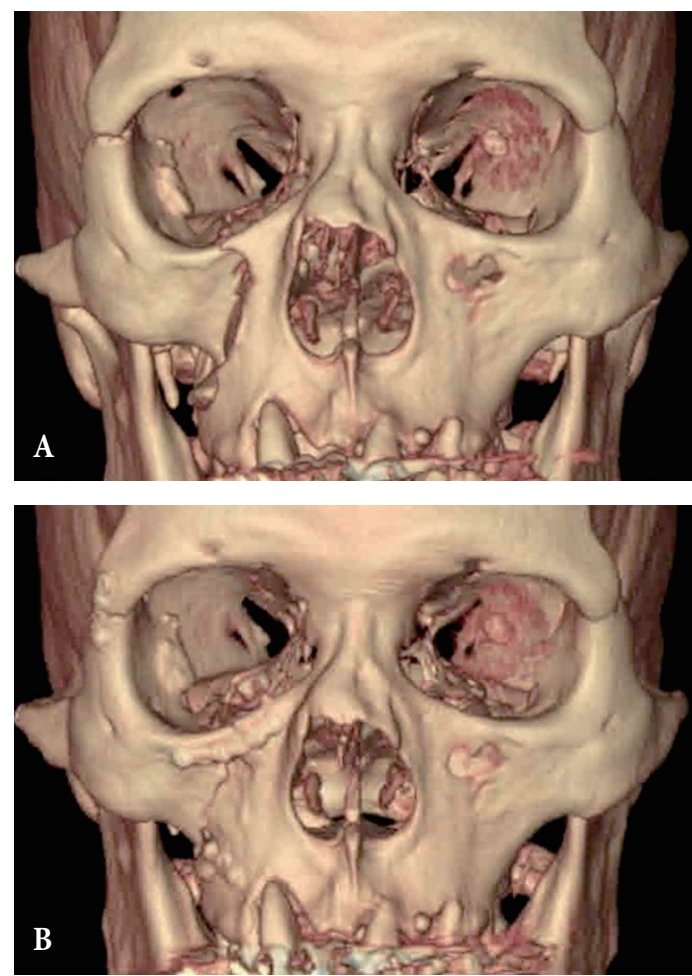

Fig. 2. Group IV zygomaticomaxillary complex fracture. (A) Preoperative computed tomography. (B) Postoperative computed tomography. The displaced and medially rotated fracture segment reduced and fixated with plates and screws. 


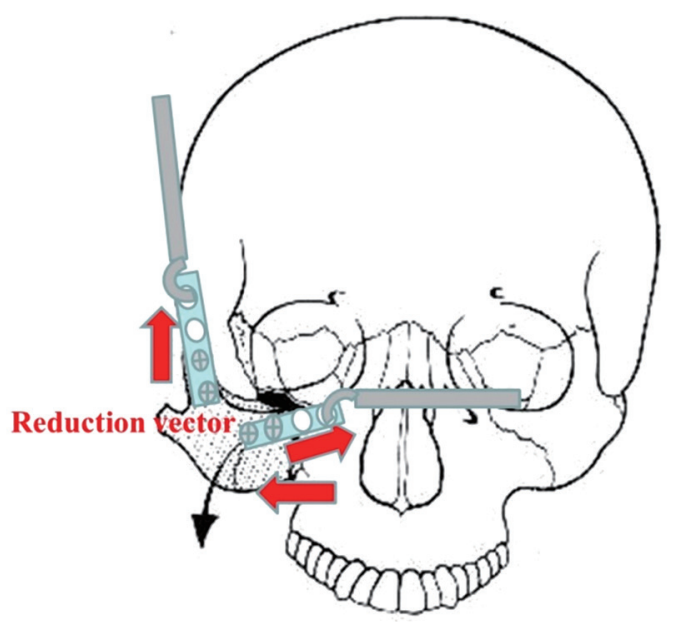

Fig. 3. Reduction with plate and screw. A $1.5 \mathrm{~mm}$ plate with a $4.0 \mathrm{~mm}$ screw fixed with the lateral fracture segment of the inferior orbital rim, and pulling the plate antero-medially with a small bone hook. After the reduction screw is fixed on the medial segment of the inferior orbital rim.
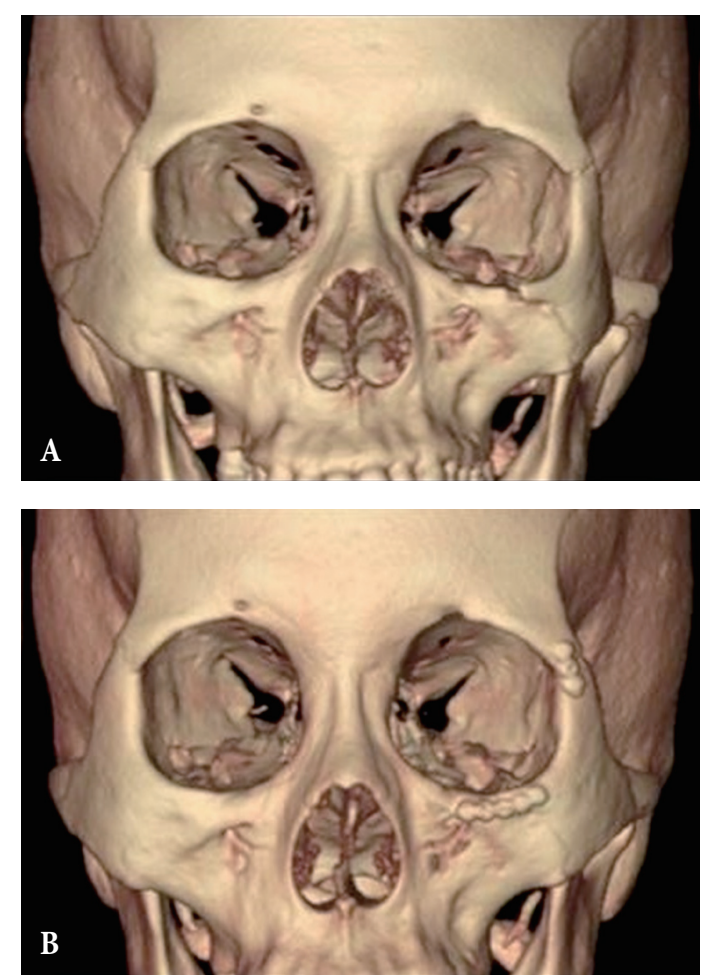

Fig. 4. Group V zygomaticomaxillary complex fracture. (A) Preoperative computed tomography. (B) Postoperative computed tomography. The displaced and laterally rotated fracture segment reduced and fixated with plates and screws.

\section{RESULTS}

The review identified 694 patients who were admitted for zygomatic fractures from which 192 patients with simple arch fractures were excluded. The remaining 502 patients consisted of 439 males and 63 females, and total 532 zygomatic bone was operated. Most patients were injured in traffic accidents followed by slip down and assault. Orbital fracture was the most common associated fracture (Table 1). According to the Knight and North classification the most frequent fracture was group IV, followed by group III, V, and VI (Table 2). When reduction of the fracture segment was stable, one point was fixated with plate and screws. Most fractures were fixated at two points (72.9\%). Unstable fracture after reduction was fixated at three points with plates and screws (Table 3). The fracture sites were approached via subcilliary incision, lateral eyebrow incision, superior gingivobuccal approach and coronal incision (Table 4). Immediate postoperative and follow up radiographic studies were also satisfactory in most patients.

Table 1. Patients' demographics

\begin{tabular}{lc}
\hline Characteristic & Patient (\%) \\
\hline Sex & \\
Male & $439(87.4)$ \\
Female & $63(12.6)$ \\
\hline Age (yr) & \\
Mean (range) & $40.2(5-87)$ \\
\hline Affected side & \\
Left & $255(50.8)$ \\
Right & $217(43.2)$ \\
Both & $30(6.0)$ \\
Cause of injury & \\
Traffic accident & $165(32.9)$ \\
Slip down & $145(28.9)$ \\
Assault & $61(12.2)$ \\
Fall & $33(6.6)$ \\
Others & $98(19.5)$ \\
\hline Associated fracture & \\
Orbital floor & $235(46.8)$ \\
Nasal bone & $120(23.9)$ \\
Mandible & $11(2.2)$ \\
Others & $50(10)$ \\
\hline
\end{tabular}


Table 2. Fracture type

\begin{tabular}{lc} 
Type of fracture & Zygoma (\%) \\
Group III & $159(29.9)$ \\
\hline Group IV & $212(39.8)$ \\
Group V & $124(23.3)$ \\
Group VI & $37(7.0)$ \\
\hline
\end{tabular}

Table 3. Fixation method

\begin{tabular}{lr} 
Fixation method & Zygoma (\%) \\
\hline 1 Point fixation & $132(16.0)$ \\
2 Point fixation & $348(72.9)$ \\
\hline 3 Point fixation & $52(11.1)$ \\
\hline
\end{tabular}

Table 4. Approach method

\begin{tabular}{|c|c|}
\hline Approach & Zygoma (\%) \\
\hline Subciliary incision & $44(8.3)$ \\
\hline Lateral eyebrow incision & $30(5.6)$ \\
\hline Superior gingivobuccal approach & $11(2.1)$ \\
\hline Subciliary incision+lateral eyebrow incision & $230(43.2)$ \\
\hline $\begin{array}{l}\text { Subciliary incision+superior gingivobuccal } \\
\text { approach }\end{array}$ & $123(23.1)$ \\
\hline $\begin{array}{l}\text { Lateral eyebrow incision+superior } \\
\text { gingivobuccal approach }\end{array}$ & $23(4.3)$ \\
\hline $\begin{array}{l}\text { Subciliary incision+lateral eyebrow } \\
\text { incision+superior gingivobuccal approach }\end{array}$ & $59(11.1)$ \\
\hline Coronal incision & $12(2.3)$ \\
\hline
\end{tabular}

\section{DISCUSSION}

The most common indication for surgery in ZMC fractures is displacement and rotation, and most displaced ZMC fractures should be treated surgically. If reduction is not performed properly, facial asymmetry will be prominent, as the result of lowering the malar prominent point [2]. For this reason, precise anatomical reduction is very important. In the formal procedure, the elevator is placed under the body through a lateral eyebrow incision and used to control the position of the body and to reduce it by upward, forward, and outward forces. Three-dimensional displacement usually occurs in ZMC fracture, meaning that malar eminence can be displaced into medial-lateral, superior-inferior, and anterior-posterior directions. For this reason, accurate reduction and fixation are possible when counterbalance direction of exter- nal force is reduced [4]. However, lateral rotation (group V) or medially severe impact will impede this procedure. In this case, the plate and screw should be used, which will result in easier assembly of the fracture alignment.

Park et al. [5] recently reported on external suspension with Steinmann pin and Kirchner wire after closed reduction. The external pin can cause discomfort for patients and experience of reduction skill is necessary. Kim et al. [6] reported reduction with a tapper using a resorbable plate procedure, the tapper is weak and there is a risk of breakage. Uda et al. [7] introduced closed reduction and internal fixation using a Carroll-Girard screw. This method used a special instrument and a small external incision on the malar eminence. A large bone hook can also be used to reduce the fracture through a small incision at the inferior margin of zygoma [8]. Rinehart et al. [9] proposed 3 point fixation to prevent masseter force. Ahn et al. [10] reduce zygoma with wire and bone hook. Their methods are similar to our methods, however, we reduce with plates and screws which used in fixation, so additional hole of the fracture segment for reduction is not necessary.

Although accurate reduction is important, a large incision and wide dissection can increase operative time and the risk of operative complications. For this reasons, various approaches are used in fixation like conjunctival incision, subcilliary incision, lateral eyebrow incision, superior gingivobuccal approach and coronal incision. Gingivobuccal incision will provide a stable zygomaticomaxillary buttress without an external scar. In this technique, aesthetically malar eminence symmetry is very important when precise reduction is performed on the lateral and inferior orbital rim. Lee et al. [11] and Langsdon et al. [12] used only conjunctival incision without external incision. It can cause some side effects, such as bradycardia, which can be caused by excessive pressure on the eyeball during the procedure. Subciliary incision can cause transient ectropion. However, it can be prevented by preserving the pretarsal portion of orbicularis oculi muscle and nerve innervation with performing layer by layer repair [13]. Many trials have been conducted over the issue of the number of fixation points. Hwang et al. [14] and Mohammadinezhad [15] insisted that one point fixation was enough. In addition, there were significant researches showing that one point or two point fixation method 
with minimal incision showed satisfactory results [16-18]. On the other hand, Choi et al. [19] used 4 point fixation for accurate correction without coronal incision. In our medical center, one or two point fixation is usually performed. Three point fixation is performed if there is unstable fracture or separation of zygomaticofrontal suture, which is more than $2 \mathrm{~mm}$. Zygomaticofrontal suture and inferior orbital rim fixate with a $1.5 \mathrm{~mm}$ small plate were used to avoid patient complaint of feeling the plates. At the zygomaticomaxillary buttress, a $2 \mathrm{~mm}$ plate was used for prevention of displacement by masseter muscle force.

In high-energy injuries with complex zygomatic fractures, laterally displaced or comminuted zygomatic arch fractures or panfacial fractures, the coronal approach is usually necessary to facilitate realignment through wide exposure. The coronal incision allows exposure of the entire zygomatic arch and roof of the glenoid fossa for precise arch reconstruction. It also exposes the zygomaticofrontalsuture and the lateral orbital wall. The major downside to this approach is the significant morbidity it potentially imparts, including scar alopecia, temporal hollowing from temporal fat pad or temporalis muscle atrophy, paresthesias, facial nerve palsies, malar descent, and displacement of the lateral canthus. For this reason, in our medical center, this approach does not used as far as possible.

The key criterion for reduction is direction of the trauma event. Reduction with plate and screw can guarantee that there is no additional incision. As I mentioned, many fixation procedures are available, however, a safe and facilitated procedure is the best way.

\section{REFERENCES}

1. Ellstrom CL, Evans GR. Evidence-based medicine: zygoma fractures. Plast Reconstr Surg 2013;132:1649-57.

2. Meslemani D, Kellman RM. Zygomaticomaxillary complex fractures. Arch Facial Plast Surg 2012;14:62-6.

3. Knight JS, North JF. The classification of malar fractures: an analysis of displacement as a guide to treatment. Br J Plast Surg 1961;13:325-39.
4. Pau CY, Barrera JE, Kwon J, Most SP. Three-dimensional analysis of zygomatic-maxillary complex fracture patterns. Craniomaxillofac Trauma Reconstr 2010;3:167-76.

5. Park BY, Song SY, Yun IS, Lee DW, Rah DK, Lee WJ. First percutaneous reduction and next external suspension with Steinmann pin and Kirschner wire of isolated zygomatic fractures. J Craniofac Surg 2010;21:1060-5.

6. Kim CY, Kim KW. Fractured facial bone reduction and resorbable plate fixation using tapper. J Craniofac Surg 2011;22:1215-8.

7. Uda H, Kamochi H, Sugawara Y, Sarukawa S, Sunaga A. The concept and method of closed reduction and internal fixation: a new approach for the treatment of simple zygoma fractures. Plast Reconstr Surg 2013;132:1231-40.

8. Ward Booth P, Schendel SA, Hausamen JE. Maxillofacial surgery. London: Churchill Livingstone; 1999.

9. Rinehart GC, Marsh JL, Hemmer KM, Bresina S. Internal fixation of malar fractures: an experimental biophysical study. Plast Reconstr Surg 1989;84:21-5.

10. Ahn HC, Youn DH, Choi MS, Chang JW, Lee JH. Wire or hook traction for reducing zygomatic fracture. Arch Craniofac Surg 2015;16: 131-5.

11. Lee PK, Lee JH, Choi YS, Oh DY, Rhie JW, Han KT, et al. Single transconjunctival incision and two-point fixation for the treatment of noncomminuted zygomatic complex fracture. J Korean Med Sci 2006;21: 1080-5.

12. Langsdon PR, Rohman GT, Hixson R, Stumpe MR, Metzinger SE. Upper lid transconjunctival versus transcutaneous approach for fracture repair of the lateral orbital rim. Ann Plast Surg 2010;65:52-5.

13. Burm JS, Kim BY, Kim YW. Prevention of lower eyelid complications caused by a subciliary approach: temporary lower eyelid suspension. J Korean Soc Plast Reconstr Surg 2006;33:465-8.

14. Hwang K. One-point fixation of tripod fractures of zygoma through a lateral brow incision. J Craniofac Surg 2010;21:1042-4.

15. Mohammadinezhad C. Evaluation of a single miniplate use in treatment of zygomatic bone fracture. J Craniofac Surg 2009;20:1398-402.

16. Hwang K, Kim DH. Analysis of zygomatic fractures. J Craniofac Surg 2011;22:1416-21.

17. Kim ST, Go DH, Jung JH, Cha HE, Woo JH, Kang IG. Comparison of 1-point fixation with 2-point fixation in treating tripod fractures of the zygoma. J Oral Maxillofac Surg 2011;69:2848-52.

18. Zhang QB, Dong YJ, Li ZB, Zhao JH. Minimal incisions for treating zygomatic complex fractures. J Craniofac Surg 2011;22:1460-2.

19. Choi KY, Ryu DW, Yang JD, Chung HY, Cho BC. Feasibility of 4-point fixation using the preauricular approach in a zygomaticomaxillary complex fracture. J Craniofac Surg 2013;24:557-62. 